\title{
The Influence of Socioeconomic Facilitations on the Opisthorchiasis Incidence on the Territory of the Khanty-Mansiysk Autonomous Okrug-Yugra
}

\author{
A. Maiurova ${ }^{1 *}$, V. Roy $^{1}$, M. Kustikova ${ }^{1}$, E. Bykovskaia ${ }^{1}$ and E. Tyurikova ${ }^{1}$ \\ ${ }^{I}$ ITMO University, 49, Kronverkskii pr., Saint Petersburg, Russia \\ "Corresponding author.Email: asmaiurova@gmail.com,marinakustikova@mail.ru
}

\begin{abstract}
This article examines the dynamics of the opisthorchiasis incidence in various districts of the Khanty-Mansiysk Autonomous Okrug-Yugra. Statistical data processing was carried out using generally accepted methods of variation statistics. All considered factors were considered for 2018. Correlation-regression analysis of the alleged socioeconomic facilitations that may affect the incidence is carried out. A spaciotemporal map of the incidence dynamics in the various regions of the KhMAO-Yugra was built to assess the dynamics of the opisthorchiasis incidence.
\end{abstract}

Keywords: socioeconomic facilitations, opisthorchiasis incidence, incidence dynamics, KhMAO, Yugra

\section{INTRODUCTION}

The goal regarding Good Health and Well-being is one of the 17 Sustainable Development Goals established by the United Nations, and an indicator of its achievement is the increase in population life extension. Reduction of the population incidence increases the productivity and welfare of society and contributes to the sustainable development of regions [1].

The liver flukes Opisthorchis felineus (Rivolta, 1884), Opisthorchis viverrini (Poirier, 1886), and Clonorchis sinensis (Loos, 1907) are Opisthorchiidae triad, they affect more than 45 million people worldwide [2]. Opisthorchiasis is caused by eating raw or undercooked freshwater fish carrying the metacercariae of the flukes, and it causes the development of autoimmune disorders, primary liver and pancreas cancer, and impaired intestinal biocenosis.

According to Federal Service for the Oversight of Consumer Protection and Welfare, two-thirds of the world area of the opisthorchiasis nature focuses is located on the territory of Russia [3]. Khanty-Mansiysk
Autonomous Okrug-Yugra (KhMAO-Yugra) is a large opisthorchiasis hyperendemic region. The presence of a natural focus of opisthorchiasis on the KhMAO-Yugra territory hinders the sustainable development of the region creating socially significant problems.

According to the state report "On the state of sanitary and epidemiological well-being of the population in the KhMAO-Yugra" opisthorchiasis accounts for $43.2 \%$ in the structure of all parasitic diseases registered in the district and $96.2 \%$ of all registered biohelminthosis. Moreover, in 2020 the opisthorchiasis incidence on the territory of KhMAOYugra exceeded the national average incidence by more than 18 times.

The factors providing a high incidence of opisthorchiasis are the violation of the technological regime of the fish production and insufficient equipping of fish processing industries with low-temperature chambers for fish preservation $[4,5]$.

According to the early studies $[5,6]$ on the territory of the KhMAO-Yugra the opisthorchiasis incidence among the population is unevenly distributed in different districts of region, the O.felineus invasion in 
fish is extremely high (up to $100 \%$ ), and contaminated fish can be purchased at regular food stores.

The life-cycle of O.felineus consists of two intermediate and one definite hosts. The first intermediate hosts are freshwater Bithynia snails ( $B$. leachi, B. troscheli, B. inflata), the second intermediate hosts are fishes of the Cyprinidae family. All carnivores can be the definite hosts [7].

One of the main issues in medical and statistical research is the complex nature of human interaction with economic progress, environment, and society. Some tasks connected with the various factors influence on the population incidence in this kind of research can be solved by means of the correlation theory and GIS technologies [8-10].

The main goal of this research is to investigate the cause-effect relations between socioeconomic facilitations and the opisthorchiasis incidence on the territory of the KhMAO-Yugra.

\section{MATERIALS AND METHODS}

The QGIS system was used to create the spaciotemporal map that allows to assess the dynamics of the opisthorchiasis incidence in the districts of KhMAO-Yugra.

Statistical data processing was carried out by means of generally accepted methods of variation statistics including the Pearson correlation coefficient. The linear correlation coefficients were estimated in accordance with the expression:

$$
r=\frac{\sum_{i=1}^{n}\left(x_{i}-\bar{x}\right) \cdot\left(y_{i}-\bar{y}\right)}{\sqrt{\sum_{i=1}^{n}\left(x_{i}-\bar{x}\right)^{2}} \cdot \sqrt{\sum_{i=1}^{n}\left(y_{i}-\bar{y}\right)^{2}}} .
$$

As the socioeconomic facilitations that may influence the opisthorchiasis incidence of population we selected:

- the number of settlements in the district;

- the number of shops selling fish;

- the population in the district;

- the number of Small Indigenous Peoples of the North (SIPN);

- the number of fishing grounds in general;

- the number of fishing grounds for traditional activities of SIPN;

- the number of fishing grounds for recreational fishing;

- the number of hospitals and clinics;

- the number of oil fields;

- the number of unemployed;
- the average monthly salary;

- the land area of the district;

- the distance from the largest cities in the district to the fishing grounds.

The incidence data were obtained from the reports "On the state of sanitary and epidemiological well-being of the population in the KhMAO-Yugra" of the Rospotrebnadzor Administration for the KhMAOYugra and statistical materials "Health of the population of the KhMAO-Yugra and the activities of medical organizations" of the Medical Information and Analytical Center.

The district incidence rate was considered as a general indicator that includes the incidence rate both of a municipal district and of urban districts located on the territory of this municipal district. For example, the incidence rate in the Surgut district includes the incidence in the Surgut city, the Kogalym city, and in general throughout the Surgutskii district.

This method of correlation estimation and indicators were chosen based on the assumption that residents of neighboring villages and urban-type settlements can seek medical care in hospitals in large cities, that the population of the region can buy contaminated fish in food stores and catch it from water bodies during recreational fishing. The incidence may also be influenced by the location of oil fields where visiting employees work on a rotational basis.

All indicators were considered for 2018. The number of cities in each region was determined by analyzing the number of points in the polygons. The number of specialized shops selling fish was estimated by means of Google Maps.

The population size, the population of Small Indigenous Peoples of the North, and the number of hospitals and clinics were obtained from the statistical materials "Health of the population of the KhMAOYugra and the activities of medical organizations" of the Medical Information and Analytical Center. The data on the number of unemployed were obtained from the statistical materials "Situation on the labor market of the KhMAO-Yugra in January-December 2019" of the Department of Labor and Employment of the KhMAOYugra.

The number of fishing grounds was obtained from the list of fishing grounds on the territory of the KhMAO-Yugra, the number of oil fields was determined according to the data of the Russian Federal Geological Fund, and the area of the municipal formation was determined according to the data of the Federal State Statistics Service. 


\section{RESULTS}

The spaciotemporal map of the incidence dynamic in the districts of the region is shown in Figure 1. The highest incidence of opisthorchiasis is annually recorded in the Sovietsky, Beloyarsky, and Nizhnevartovsky Districts. Most of the new cases of opisthorchiasis detection occur in the autumn period, which is explained by the increased sale of caught fish.

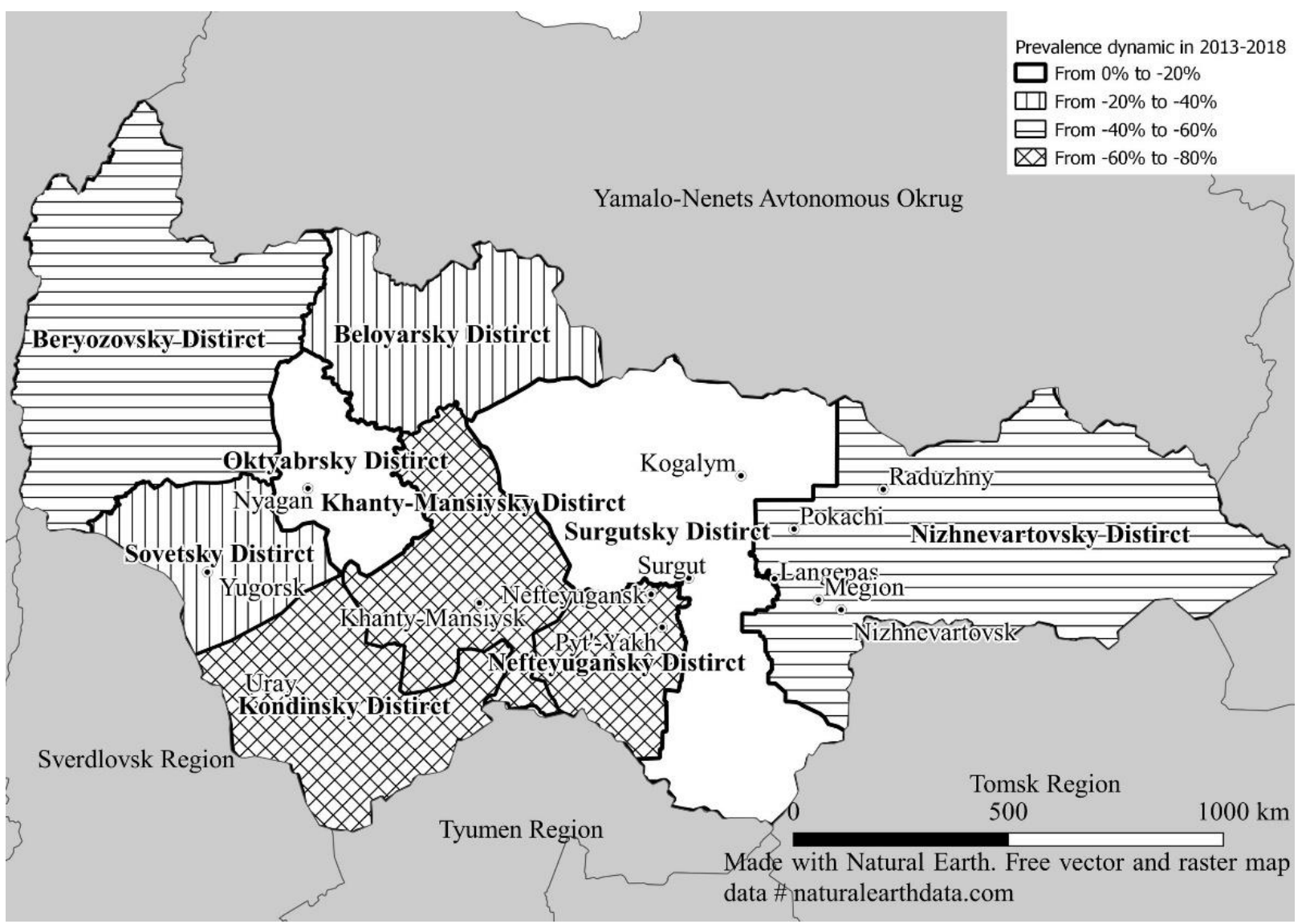

Figure 1. Spaciotemporal map of the incidence dynamic in the districts of the KhMAO-Yugra

Over the past seven years, there has been a tendency towards a decrease in the incidence of opisthorchiasis both in the KhMAO-Yugra and in general on the territory of Russia. However, many healthcare organizations associate this fact rather with violations in the registration system of new cases and with an increase in the population than with an increased awareness of the population about the causes of the disease and with an improvement in the conditions of disinfecting equipment at fish processing enterprises.

The incidence rates of opisthorchiasis per 100 thousand people and the selected socio-economic indicators are presented in Table 1.

The calculated correlation coefficients are presented in table 2. Most of the selected socio-economic indicators do not significantly affect the incidence. Most of the coefficients indicate a weak inverse relationship between the factors and the incidence. On the Chaddock scale only two correlation coefficients indicate a noticeable effect of the factors on the incidence.

The table shows that the number of specialized fish stores has the greatest influence on the incidence rate, which may indicate that these stores sell insufficiently processed fish with living opisthorchid metacercariae. The correlation coefficient of the incidence and the number of settlements can be considered as another significant indicator. It can be assumed that city dwellers are paying more careful attention to the correct processing of fish. 
Table 1. Socio-economic indicators for estimation of incidence dependence on socioeconomic facilitations

(a)

\begin{tabular}{|l|l|l|l|l|}
\hline District & $\begin{array}{l}\text { Incidence per 100 } \\
\text { thousand people }\end{array}$ & Qty of settlements & Population & $\begin{array}{l}\text { Population of } \\
\text { SIPN }\end{array}$ \\
\hline 1. Beloyarsky & 763.17 & 13 & 28,434 & 2,802 \\
\hline 2. Berezovsky & 292.19 & 25 & 22,246 & 5,593 \\
\hline 3. Kondinsky & 189.47 & 28 & 71,071 & 5,775 \\
\hline 4. Nefteyugansky & 192.83 & 12 & 212,091 & 1,179 \\
\hline 5. Nizhnevartovsky & 365.64 & 26 & 472,990 & 3,294 \\
\hline 6. Oktyabrsky & 316.26 & 23 & 86,646 & 2,386 \\
\hline 7. Sovetsky & 863.77 & 11 & 85,576 & 540 \\
\hline 8. Surgutsky & 203.02 & 28 & 565,356 & 4,275 \\
\hline 9. Khanty-Mansiysky & 283.20 & 31 & 119,385 & 4,802 \\
\hline
\end{tabular}

(b)

\begin{tabular}{|l|l|l|l|l|}
\hline District & $\begin{array}{l}\text { Qty of fishing } \\
\text { grounds in general }\end{array}$ & $\begin{array}{l}\text { of which for traditional } \\
\text { activities of SIPN }\end{array}$ & $\begin{array}{l}\text { of which for } \\
\text { recreational fishing }\end{array}$ & $\begin{array}{l}\text { Qty of } \\
\text { hospitals }\end{array}$ \\
\hline 1. Beloyarsky & 210 & 135 & 24 & 2 \\
\hline 2. Berezovsky & 634 & 150 & 56 & 2 \\
\hline 3. Kondinsky & 648 & 42 & 56 & 4 \\
\hline 4. Nefteyugansky & 134 & 56 & 56 & 4 \\
\hline 5. Nizhnevartovsky & 740 & 2 & 69 & 14 \\
\hline 6. Oktyabrsky & 205 & 21 & 77 & 4 \\
\hline 7. Sovetsky & 130 & 6 & 124 & 5 \\
\hline 8. Surgutsky & 530 & 361 & 42 & 15 \\
\hline 9. Khanty-Mansiysky & 629 & 7 & 117 & 7 \\
\hline
\end{tabular}

(c)

\section{District}

1. Beloyarsky

2. Berezovsky

3. Kondinsky

4. Nefteyugansky

5. Nizhnevartovsky

6. Oktyabrsky

7. Sovetsky

8. Surgutsky

9. Khanty-Mansiysky

\section{Average monthly salary, rub}

\begin{tabular}{|l}
74,100 \\
\hline 63,500 \\
\hline 55,900 \\
\hline 61,300 \\
\hline 53,000 \\
60,700 \\
\hline 63,100 \\
74,900 \\
\hline 70,000
\end{tabular}

Land area, $\mathrm{m}^{2}$

Qty of oil fields $\quad$ Qty of unemployed

\begin{tabular}{|l|l|l|}
\hline 41,646 & 14 & 492 \\
\hline $88,100.5$ & 1 & 738 \\
\hline $54,627.4$ & 39 & 947 \\
\hline 24,548 & 49 & 455 \\
\hline $117,212.2$ & 155 & 2,159 \\
\hline $24,502.1$ & 33 & 1,693 \\
\hline 30,100 & 30 & 2,017 \\
\hline $104,997.5$ & 176 & 1,583 \\
\hline 46,064 & 38 & 980 \\
\hline
\end{tabular}

Table 2. Dependence of the opisthorchiasis incidence on various factors

\begin{tabular}{|l|l|l|l|}
\hline Indicator & $\begin{array}{l}\text { Pearson's correlation } \\
\text { coefficient }\end{array}$ & Indicator & $\begin{array}{l}\text { Pearson's correlation } \\
\text { coefficient }\end{array}$ \\
\hline Qty of settlements & -0.66 & Distance from fresh water bodies & -0.11 \\
\hline Population & -0.34 & Qty of specialized fish stores & 0.68 \\
\hline Population of SIPN & -0.55 & Average monthly salary & 0.22 \\
\hline Qty of fishing grounds in general & -0.51 & Land area & -0.30 \\
\hline of which for traditional activities of SIPN & -0.20 & Qty of oil fields & -0.31 \\
\hline of which for recreational fishing & 0.23 & Qty of unemployed & 0.20 \\
\hline Qty of hospitals & -0.27 & & \\
\hline
\end{tabular}

factors affecting the spread of biohelminthiasis on various territories.

\section{CONCLUSION}

The spread of some natural focal diseases largely depends on human activity. Population migration and socio-economic living conditions of people are the main
The spreading of opisthorchiasis in the KhMAOYugra is caused by the migration of the population associated with the development of oil and gas fields, with the food culture of the SIPN, low level of 
awareness of the population, with low coverage of diagnostics and treatment of the population as well as with the lack of modern sewage treatment facilities in many settlements of the district.

It was discovered that the correlation coefficient between most of the selected socioeconomic facilitations is quite low. The most representative facilitations are the number of stores selling fresh fish and the number of settlements on the territory of the municipalities of the KhMAO-Yugra.

The presence of a significant relationship between the number of fish shops and incidence serves as the basis for compliance test of the goods with sanitary standards and rules as well as for increasing educational work with the population of the region.

\section{REFERENCES}

[1] J. Menash, Sustainable development: Meaning, history, principles, pillars, and implications for human action: Literature review, Cogent. Soc. Sci. 5 (2019) 1-21.

[2] T.N. Petney, R.H. Andrews, W. Saijuntha et al., The zoonotic, fish-borne liver flukes Clonorchis sinensis, Opisthorchis felineus and Opisthorchis viverrini, Int. J. Parasitol. 43 (2013) 1031-1046.

[3] V.A. Mordvinov, N.I. Yurlova, L.M. Ogorodova, A.V. Katokhin, Opisthorchis felineus and Metorchis bilis are the main agents of liver fluke infection of humans in Russia, Parasitol. Int. 61 (2012) 25-31.

[4] L.M. Ogorodova, O.S. Fedorova, B. Sripa et al., Opisthorchiasis: An Overlooked Danger, PLoS Negl. Trop. Dis. 9 (2015) e0003563.

[5] M.Y. Pakharukova, V.A. Mordvinov, The liver fluke Opisthorchis felineus: biology, epidemiology and carcinogenic potential, Trans. R Soc. Trop. Med. Hyg. 110 (2016) 28-36.

[6] A.S. Maiurova, Assessment of the invasion extensiveness by Opisthorchis felineus metacercaries of cyprinidae family fish sold in grocery stores in Khanty-Mansiysk, Bull. RSHU 97 (2019) 91-97.

[7] I.I. Brusentsov, A.V. Katokhin, I.V. Brusentsova et al., Low genetic diversity in wide-spread eurasian liver fluke opisthorchis felineus suggests special demographic history of this trematode species, PLoS ONE 8 (2013) e62453.

[8] P. Goovaerts, Medical geography: a promising field of application for geostatistics, Math. Geol. 41 (2009) 243-264.
[9] A.W. Hightower, R.E. Kline, Building a geographic information systems (GIS) public health infrastructure for research and control of tropical diseases, Emerg. Infect. Dis. 1 (1995) 156.

[10] S. Dearwent, R. Jacobs, J. Halbert, Locational uncertainty in georeferencing public health datasets, J. Expo Sci. Environ. Epidemiol. 11 (2001) 329-334. 